\title{
TOWARD A MEDIUM-TERM AGRICULTURAL AND RURAL DEVELOPMENT STRATEGY
}

Paul Dorosh and Bart Minten

\section{Introduction}

Ethiopia has invested heavily in agriculture and the rural economy since the early 1990s. These investments have largely paid off. The provision of inputs and new technologies have enabled rapid agricultural production growth. Investments in road infrastructure and increased demand for agricultural products have led to a large expansion in the value of sales. Public investments in urban infrastructure have also contributed to a large expansion in economic activity and the number of secondary cities. Effective safety nets have enhanced household food security and improved resilience to droughts and other shocks. Lastly, macroeconomic policy has been broadly stable as adjustments to exchange rates, foreign borrowing, and public expenditures have kept macroimbalances from growing large enough to substantially hinder growth.

Looking forward, however, Ethiopia faces several major challenges related to rural (and overall) poverty reduction. Increasing population pressure will limit land availability and increase food demand, necessitating continued gains in both land and labor productivity. In the longer term, climate change is not expected to affect average yields, but the incidences of shocks are expected to increase (Chapter 4). At the same time, the Ethiopian food system is rapidly transforming from relatively low productivity cereal and small-scale livestock farms with little marketed output toward high productivity, diversified, market-oriented agriculture closely linked with major urban centers and international markets. As the food economy expands, the differences in resource constraints and market opportunities will become more pronounced. Addressing these challenges and managing structural changes to the rural economy will depend on key investments and policies and necessitate a regionally differentiated, food system approach. 


\section{Sustainable Growth in Agricultural Production}

Although Ethiopia has succeeded in rapidly increasing agricultural production over the past decade (Chapter 3), a number of actions are needed to feed a growing population. Increasingly important is also the composition of agricultural production. Most agricultural growth has been concentrated in the cereal sector. As the Ethiopian population becomes richer and more urbanized, the demand of high-value products such as animal-sourced foods, fruits, and vegetables is expected to increase. However, production of these highvalue products has been slow in the past decade, as evidenced by their increasing prices (Chapter 7). To ensure that this increased demand can be met by local supply and not by imports, several key investments and policies will be needed, especially those that are gender-sensitive as empowering women in agriculture has been shown to have payoffs for agricultural outcomes (Aguilar et al. 2015).

Most crops have not reached their yield potential, indicating that there is still a significant opportunity to increase production (Chapter 3). Fertilizers adapted to local soil conditions are needed as are higher adoption rates of improved seeds. To stimulate adoption of both, better supply and marketing conditions are required. On the supply side, more resources should be channeled to the development of improved seeds by local public researcher centers given the high returns (Alston et al. 2000). A more active role for the private sector is required as well, particularly in the development of hybrids. Publicly available soils maps and extension agents knowledgeable of local conditions can help tailor fertilizer recommendations for farmers to increase efficiency. In the medium-term, increased coordination between knowledge centers, agricultural extension workers, and farmers will also be needed (Chapter 3). Moreover, better marketing that involves the private sector can help lower costs, enhance choice and improve distribution. This might imply, among others, better regulations and conditions for firms involved in the import of agricultural inputs such as seeds, agrochemicals, and machinery, creating a level playing field for the private and public sector, and embracing enhanced choice and competition in the distribution of agricultural inputs.

Intensifying agricultural productivity on limited land will also require the development of new technologies as well as more widespread adoption of improved agronomy/management practices already "on the shelf." Mechanized production and postharvest activities are currently low. However,

1 Soil mapping and microlevel soil recommendations have been developed by the Agricultural Transformation Agency (ATA), as discussed in Chapter 3. 
as shown in Chapter 11, the transformation of Ethiopia's rural economy is rapidly leading to higher rural wages incentivizing labor-reducing technologies (Ruttan and Hayami 1984). This trend can already be seen by the increasing adoption of herbicides in commercial agricultural areas as a substitute for weeding labor, but it will also drive mechanization during planting and harvesting periods when demand is highest.

Again, both the public and private sector will have important roles to play in making inputs available to farmers at affordable prices. Ethiopia is currently underinvesting in agricultural research (Chapter 3), and more efforts are needed to develop and adapt innovations making them suitable for local users. As part of this effort, the innovation system's link with the extension system as well as the private sector should be institutionalized and strengthened (Berhane et al. 2018). The private sector understands what types of technologies are needed and ultimately will be responsible for their manufacture, distribution, and repair and must be seen as an essential partner.

Agricultural land expansion has decelerated in recent years, putting more pressure on available land in the highlands (Chapters 2 and 6). Important land reforms and the implementation of a large-scale land certification program have helped to ensure more secure property rights, and Kumar and Quisumbing (2015) show that reforms in the law and land registration have been an important avenue to improved gender equality in Ethiopia. This land certification program has been one of the largest, cheapest, and fastest in Africa (Deininger et al. 2008). ${ }^{2}$ However, as populations continue to increase, it will be necessary to monitor land tenure rules to ensure their suitability with transforming agrifood systems. At the same time, land in less accessible regions but with sufficient rainfall such as parts of the western regions (Gambella and Benishangul-Gumuz, and the Oromia region) and in the dryer lowlands remains underexploited because of poor access to water, road infrastructure, and services. Infrastructure and irrigation investments that tap into these areas' latent potential will stimulate production but also support pastoral economies that play an important role in supplying animal-sourced foods. To reach their full potential, livestock systems will also require broader adoption of improved animal husbandry and feeding practices, increased production of genetically superior breeds of livestock, and the provision and use of appropriate veterinary health practices. Given the high perishability of these

2 Although land stayed the property of the state, these certificates have ensured more secure property rights as they have been found to have led to higher investments, more land rental market activity, higher productivity, and improved food security (Deininger, Ayalew, and Alemu 2011; Ghebru and Holden 2013). 
products, investments will be needed toward new off-farm technologies, such as cold storage and processing.

\section{Modernization of Agricultural and Food Markets}

Most of the attention in past agricultural strategies has gone toward increasing agricultural supply, and the off-farm segment in agrifood systems has received relatively less attention. This was justified given the high level of autoconsumption of agricultural products by the average Ethiopian, who was typically a farmer living in a rural area. Such a low share of purchases (and sales) and very high transport and marketing costs limited potential growth linkages, particularly for small farmers, as increases in their production did not lead to substantially higher incomes for processors, transporters, and traders. However, as shown in Chapters 7 and 10, this is changing rapidly; already in 2016, the average Ethiopian acquired more than half of her calories from purchased food. Livestock product markets are also expanding rapidly. These trends are expected to continue and more policy attention toward ensuring efficiently functioning value chains is therefore required. While the performance of agricultural markets has improved enormously in the past decade, it is expected that growing incomes, population growth, urbanization, and better infrastructure will lead to a massive expansion of agricultural and food markets, and the agrifood system more broadly, and might therefore strain the existing system. A number of actions could be taken to facilitate that expected transformation and upscaling process and to improve agricultural and food markets.

Ethiopia's development model involving heavy public sector involvement was well-suited for addressing the major constraints on agricultural growth prior to 2010. At that time, weak road infrastructure required massive public investments. Reliance on traditional varieties of major cereals could be addressed with large-scale distribution of improved, open-pollenated varieties (not hybrids). And increased use of basic nitrogen and phosphate fertilizer was sufficient to produce major increases in yields.

However, this heavy public sector involvement was accompanied by policies that crowded out activities by the private sector, as seen in preferential treatment for access to credit allocations, foreign exchange, and land (World Bank 2015). While the public sector has an important role to play in stimulating agricultural growth, it typically lacks the information and incentives to allocate goods and services efficiently in agricultural and food markets. The public sector is best suited to ensure a competitive environment that enables the private sector to deliver goods and services more efficiently and with 
greater choice. However, private-sector development has been problematic as shown by a global assessment of the ease of doing business in which Ethiopia was ranked 159th of 190 countries in 2018 (World Bank 2019).

With the rapid transformation of the agriculture-food system, a new development model is needed-one led by the private sector supported by profarmer and pro-business policies and public investments. Agricultural and broad economic policy will require greater transparency and consistency. Rapid, broad-based growth will also require a level playing field across subsectors (various crops and livestock) and regions that encourages participation of thousands if not millions of actors, so as to promote investments in a very wide array of high-value products throughout many parts of Ethiopia. The establishment of industrial and agro-industrial parks was a good first step (Chapter 12), but there is also scope for investment outside these centers. As part of this, an increasing role for more modern supply chains and the retail trade could deliver a number of these foods at significantly lower prices to consumers, with potential benefits for producers as well (Minten and Reardon 2008; Reardon et al. 2009).

Food quality and safety will also become more important requirements in the agricultural food system given the changes in products, in value chains with increasing long-distance transport and storage requirements, and in consumer demands (Chapter 7). Making sure that appropriate institutions, regulations, certification and traceability mechanisms, infrastructure, and awareness are present to allow for the delivery of safe products is an important challenge for the future in these rapidly transforming and emerging markets.

As Ethiopia's economy grows and urbanization takes off, more attention needs to be paid to the off-farm aspect of agricultural value chains. These off-farm activities have important impacts on employment (often of young people) as well as on prices and food security for both urban and rural populations. Rapidly emerging agrifood small and medium-sized enterprises in this off-farm segment add significant value, but they are often neglected in the African food debate (Reardon et al. 2015).

\section{Reducing Poverty and Malnutrition}

Although economic growth has lifted a significant number of people further out of poverty, there is still a need to have well-functioning and targeted safety nets in place that will address the needs of vulnerable and poor households, especially in light of increased climate variability. Ethiopia has had important successes in the implementation of the Productive Safety Net Program (PSNP) in the past decade, but further adjustments might be needed moving 
forward. ${ }^{3}$ First, given rapid urbanization, a large number of poor people are now living in urban areas, and further ensuring coverage by urban safety nets-as has recently been started - is seemingly needed. Second, as agricultural markets are now functioning better than before, infrastructure (communication as well as road) has significantly improved, and there are cost savings in delivering cash payments (compared with food) to targeted households, a further move toward cash payments for safety-net recipients seems warranted. Third, an improved early warning system, disaster risk management, and coordination between safety net and emergency aid relief seems needed. Finally, maintaining incentives for private-sector trade (including wheat imports) in times of crop shortages and high prices can potentially mitigate adverse price effects on consumers following droughts (Chapter 9). ${ }^{4}$

Moreover, despite high growth rates in agricultural production and significant reductions in poverty, the slow change in nutritional indicators and the high level of stunting in the country remain a major concern, especially in rural areas (Chapter 10; Hirvonen et al. 2019). More attention should therefore be paid to how agricultural growth can enhance food diversity and nutritional indicators. While there are still a number of unknowns on how this nutritional transformation can be most efficiently achieved, it seems that behavioral change communication, gender considerations, sanitation, improved market access, and agricultural production diversity, especially in less connected areas, should have a major role to play.

\section{Macroeconomic Policy and Development Strategy}

Maintaining macroeconomic incentives and stability is a prerequisite for sustained economic growth, which in turn is crucial to promote market demand for agricultural products. Broad economic growth, including growth in the nonagricultural economy, is thus a necessary condition for successful agricultural growth and poverty reduction. With appropriate policies and investments, Ethiopia's agriculture-food system and the overall economy could

3 The decline in poverty rates and malnutrition has not been accompanied by a major increase in average calorie consumption (mean caloric intake rose by only 1 percent between 2011 and 2017), reflecting in part the increase in meat consumption as well as the impact of timely targeted transfers. It may also reflect improvements in sanitation and feeding practices for young children.

4 As discussed in Chapter 9, wheat imports in most years were used almost exclusively for targeted transfers. In 2014/2015, government wheat imports accounted for 20.1 percent of net wheat supply (and 4.8 percent of net cereal supply). The volume of additional grain supplied in $2015 / 2016$ in response to the drought was substantial (2.5 million metric tons of imports compared with 950,000 metric tons in 2014/2015) and lowered prices by an estimated 26.0 percent (Simulation S2, Table 9.12). 
prosper. Avoiding a major surge in inflation and potential debt and balanceof-payments problems will require a major reduction in public sector borrowing and net foreign capital inflows-policy shifts that will likely entail a slowdown in economic growth as well. ${ }^{5}$ Maintaining a strongly positive investment climate will require that enterprises and new investors have ready access to foreign exchange with minimal delays or costs of import licenses (currently a major constraint for many commercial firms).

Finally, managing the rural-urban transformation and the overall structural transformation of the economy will require appropriate public investments in rural as well as urban infrastructure. Policies outside the agricultural sector will be essential for this transformation and for long-term growth (Chapters 12 and 13). These policies include education policies and investments, strengthening the legal framework for business and investment, and investments in ports. Depending on broad political considerations, road and rail connections to Eritrea's ports may provide new opportunities to reduce costs of international trade. Particularly important will be electricity generation and distribution policies. Solar energy may offer important opportunities to provide electrification to small towns and relatively remote rural areas.

\section{Implications for Development Strategy in Other African Countries}

Although Ethiopia's highland agroecology differs from that of much of the rest of Africa, the basic ingredients of Ethiopia's successful agricultural and rural development are applicable to many other African countries. Most important is Ethiopia's sustained commitment to the agricultural sector through public investments in agricultural research and extension, ensuring wide access to fertilizer and improved seeds, and investment in rural roads. Second, Ethiopia has largely avoided market distortions such as imposition of official market prices and large-scale imports that have taxed producers in many other African countries. As discussed in Chapter 9, price interventions in wheat have helped Ethiopia limit price spikes following droughts, but the scale of interventions in other major cereal markets has been minimal. Third, Ethiopia's Productive Safety Net Program has effectively targeted food-insecure households, enhancing their food security. Finally, in comparison to other African countries (such as Nigeria, Zambia, Zimbabwe, and the

5 Note that all simulations in Chapter 13 assumed some slowdown in capital inflows, and sensitivity analysis showed that major results were not affected by moderate changes in capital flows. 
Democratic Republic of the Congo), Ethiopia has enjoyed both broad macroeconomic and political stability over most of the past two decades. ${ }^{6}$

\section{Conclusion}

Given that significant yield gaps remain for major crops and livestock and dairy productivity remains low, public investments in agriculture are likely to continue to have a high payoff. Moreover, even with continued changes in economic structure due to increased incomes, urbanization, and improved infrastructure, agricultural investments are likely to continue to be strongly pro-poor given the concentration of poverty in rural areas. Agricultural investments will likely continue to result in greater poverty reduction than investments in urban sectors, at least through the mid-2020s. If economic growth slows in the coming decade, the dominance of agriculture as a pro-poor investment will likely continue until 2030 and beyond. Moreover, investments in the broader agrifood sector (including investment in roads and electricity in small towns and periurban areas) are even more pro-poor than investments restricted to agricultural production and should continue.

Massive changes have taken place in Ethiopia's economy. Land constraints are becoming increasingly binding, especially in the highlands, implying a likely deceleration in agriculture growth. With rural population projected to increase despite continued urbanization, average farm size will likely decrease. Rapid growth in the nonagricultural economy will likely result in a sharp increase in market demand for agricultural products. Continued massive urban investments can result in further economic growth and structural transformation, particularly if macroeconomic stability and incentives for private investment are maintained. But without considerable investments in the rural farm and nonfarm economy, it will be very difficult to achieve rapid poverty reduction.

In short, though rapid economic growth and structural transformation have diminished the relative importance of the agricultural sector in Ethiopia's economy, continued public investments in agriculture and the broader agrifood system (for example, agricultural research and extension, particularly in high-value crops and livestock, and rural and secondary city transport infrastructure and electricity supply) remain crucial for equity and poverty alleviation in Ethiopia. A favorable climate for private investment is also needed, including stable macroeconomic and trade policy, access to credit

6 There has been a recent upsurge in political instability since mid-2019, however. 
and foreign exchange, and avoidance of policy changes that increase riskiness of investments. If poverty reduction is still a top priority, it is too soon to reduce the level of agricultural and rural investment in Ethiopia.

\section{References}

Aguilar, A., E. Carranza, M. Goldstein, T. Kilic, and G. Oseni. 2015. "Decomposition of Gender Differentials in Agricultural Productivity in Ethiopia." Agricultural Economics 46 (3): 311-334.

Alston, J. M., C. Chan-Kang, M. C. Marra, P. G. Pardey, and T. J. Wyatt. 2000. A Meta-Analysis of Rates of Return to Agricultural R\&D: Ex Pede Herculem? Volume 113. Washington, DC: International Food Policy Research Institute (IFPRI).

Berhane, G., C. Ragasa, G. T. Abate, and T. W. Assefa. 2018. The State of Agricultural Extension Services in Ethiopia and Their Contribution to Agricultural Productivity. ESSP Discussion Paper 118. Adds Ababa: IFPRI.

Deininger, K., D. Ayalew, and T. Alemu. 2011. "Impacts of Land Certification on Tenure Security, Investment, and Land Market Participation: Evidence from Ethiopia." Land Economics 87 (2): 312-334.

Deininger, K., D. Ayalew, S. Holden, and J. Zevenbergen. 2008. "Rural Land Certification in Ethiopia: Process, Initial Impact, and Implications for Other African Countries." World Development 36 (10): 1786-1812.

Ghebru, H., and S. Holden. 2013. Links between Tenure Security and Food Security: Evidence from Ethiopia. IFPRI Discussion Paper 1288. Washington, DC: IFPRI.

Hirvonen, K., D. Headey, J. Golan, and J. Hoddinott. 2019. "Changes in Child Undernutrition in Ethiopia (2000-2016)." In The Oxford Handbook of the Ethiopian Economy, edited by C. Cramer, F. Cheru, and A. Oqubay, 399-411. New York: Oxford University.

Kumar, N., and A. R. Quisumbing. 2015. "Policy Reform Toward Gender Equality in Ethiopia: Little by Little the Egg Begins to Walk." World Development 67: 406-423.

Minten, B., and T. Reardon. 2008. "Food Prices, Quality, and Quality's Pricing in Supermarkets versus Traditional Markets in Developing Countries." Review of Agricultural Economics 30 (3): 480-490.

Reardon, T., C. B. Barrett, J. A. Berdegué, and J. F. Swinnen. 2009. “Agrifood Industry Transformation and Small Farmers in Developing Countries." World Development 37 (11): $1717-1727$. 
Reardon, T., D. Tschirley, B. Minten, S. Haggblade, S. Liverpool-Tasie, M. Dolislager, and C. Ijumba. 2015. "Transformation of African Agrifood Systems in the New Era of Rapid Urbanization and the Emergence of a Middle Class." In Proceedings of the ReSAKSS Annual Conference, "Beyond a Middle Income Africa," Trends and Outlook Report, 1-16. Conference in Addis Ababa, September 1-3.

Ruttan, V. W., and Y. Hayami. 1984. "Toward a Theory of Induced Institutional Innovation.” Journal of Development Studies 20 (4): 203-223.

World Bank. 2015. Ethiopia's Great Run: The Growth Acceleration and How to Pace It. Report no. 99399-ET. Washington, DC.

- 2019. Doing Business 2019: Training for Reform, 16th ed. Washington, DC. 